\title{
EXPLORING PERCEPTIONS OF PARENTS ON THE USE OF EMERGENCY DEPARTMENT ON-SITE PRIMARY CARE SERVICES FOR THE TREATMENT OF CHILDREN WITH NON-URGENT CONDITIONS
}

\author{
AUTHORSHIP \\ Ms Mfon Sam ${ }^{1}$ \\ Ms Dianne L Cook 2,3 \\ Professor Andrew G Rowland 2,3,4 \\ Dr James Butler ${ }^{5}$
}

1 Research and Innovation Department, Trafford General Hospital, Manchester University NHS Foundation Trust, Moorside Road, Davyhulme, Manchester M41 $5 S L$, UK

2 Emergency Department, North Manchester General Hospital, The Pennine Acute Hospitals NHS Trust, Delaunays Road, Manchester, M8 5RB, UK

3 School of Health and Society, Mary Seacole Building, Frederick Road Campus, The University of Salford, Salford, M6 5ST, UK

4 Research and Innovation Department, The Northern Care Alliance NHS Group, Salford, Summerfield House, Eccles New Road, M5 5AP, UK

5 Emergency Department, The Royal Oldham Hospital, The Northern Care Alliance NHS Group, Oldham, OL1 2JH, UK

\section{CORRESPONDING AUTHOR}


Professor Andrew Rowland, School of Health and Society, Mary Seacole Building, Frederick Road Campus, The University of Salford, Salford, M6 5ST, UK A.Rowland@salford.ac.uk

\section{AUTHORSHIP CONTRIBUTIONS}

MS: Co-devised the concept of the study, carried out the research including analyzing the data and produced the first draft of the manuscript.

AGR: Co-devised the concept of the study and contributed to the drafting of the manuscript.

DC: Supported data collection and contributed to the drafting of the manuscript.

JB: Co-devised the concept of Same Day Care services at North Manchester General Hospital and and contributed to the drafting of the manuscript.

All authors: approved the final manuscript prior to submission.

MS is the guarantor.

\section{DECLARATION OF INTERESTS}

None of the authors have any conflicts of interest to declare.

\section{KEY WORDS}

Urgent Care Centre

Paediatrics

Emergency Department

Primary Care

Emergency Medicine 


\section{FUNDING}

This study received no specific grant, or any funding, from any agency in the public, private or not-for-profit sector. This study was entirely unfunded.

\section{WHAT RESEARCH ALREADY TELLS US ABOUT THIS SUBJECT}

- Parents and professionals acknowledge the importance of closer liaison between hospital and primary health care services.

- Healthcare professionals have suggested lack of primary care appointments and parents' lack of knowledge of conditions that are true emergencies as reasons children attend emergency departments.

- There is potential benefit of clinical and cost savings from on-site primary care services through limited use of diagnostics and referrals for admission.

- Of those EDs with integrated primary care services, reduced wait times, timely care, patients' satisfaction and effective use of resources have been reported.

\section{WHAT THIS PAPER ADDS}

- Seeking advice from someone prior to ED attendance was not a major determinant of parents attending the ED.

- Parents will welcome care from paediatric on-site same day care service for their sick children if appropriate.

- The ED is considered a default option for parents perceived children's emergencies.

\section{REVALIDATION CPD REFLECTIVE QUESTIONS}


These questions are included to enable regulated healthcare professionals to consider learning they may have gained from reading this paper. The questions are formulated in a way to enable regulated professionals to consolidate their learning from this paper in a way that may be helpful for their portfolios of continuing professional development evidence, perhaps as part of revalidation procedures or other processes required by either their employer or regulator.

- Across the UK, emergency systems are under considerable pressure, with ED attendances for minor illnesses being a significant contributor to pressures. What are the contributing factors that may be local to your own hospital?

- What do you believe makes a parent decide to bring a child with a minor illness to a hospital ED rather than providing self-care at home or going to a GP or pharmacy?

- The terms non-urgent, unnecessary and inappropriate attendances are often used synonymously. As a healthcare professional, what do you consider to be a 'non-urgent' attendance to an ED? Can you recognise how your perspectives of 'non-urgent' may differ to that of an anxious, distressed parent? 


\section{ABSTRACT}

\section{Objective}

To understand the reasons parents of children with minor conditions attend the Children's Emergency Department (ED), and their views about on-site paediatric same day care (SDC) service as an alternative treatment centre.

\section{Method}

A cross-sectional survey of parents attending an inner-city, district general hospital children's ED, with children aged under 16 years old who were allocated to low triage categories. A convenience sample of 58 parents of 58 children were recruited.

\section{Results}

All the 58 responses were analysed. Incomplete questionnaires were not excluded. $47 \%$ of attendances were because of minor injury. Most presentations were within 24 hours of the injury or illness. $72 \%$ of parents were employed. $91 \%$ were registered with a General Practitioner (GP). 29\% contacted a GP before the ED visit. The majority of participants who contacted a GP were referred to the ED; others were advised to wait to see if the child's condition improved and to attend the ED if there were any concerns or the child deteriorated in any way. $50 \%$ of those that did not contact GP said the GP surgery was closed and $8 \%$ felt the GP could not help. $90 \%$ of parents perceived their child's condition as urgent requiring immediate treatment. $33 \%$ of parents said they would be happy for their children to be treated at an on-site Same Day Care (SDC) Centre.

\section{Conclusions}


The study showed limited access to GP services in the community and dissatisfaction with community services and perceived urgency of treatment prompted parents of children with minor conditions to attend the ED. This could mean significant ED attendance by children with minor conditions. The majority of the parents in the study would welcome an on-site paediatric SDC if appropriate to meet their children's care needs. Establishing an on-site SDC may help relieve the ED pressures to attend to more clinically urgent and emergency cases. 


\section{INTRODUCTION}

Emergency Departments (EDs) in England are experiencing unprecedented pressures due to increased numbers of patients seeking care (1, 2). In 2018/2019, an estimated 24.8 million people were cared for in EDs. in England, representing an increase of four per cent compared with 2017/2018 and 21 per cent since 2009/2010 to three years previously (3). It has been proposed that between 1.5 and 3 million people who come to ED each year could have their needs addressed in other urgent care facilities (4-6). Globally throughout children's emergency medicine, there is growing concern about the significant rise in the number of children that attend EDs with non-emergency conditions (1). In England, over 5 million children attend EDs annually and approximately $60 \%$ of them present with non-urgent illnesses creating increased burden on children's EDs (7). An American study suggested each day over 69,000 children attend an ED, with $58 \%$ to $82 \%$ of them for non-urgent reasons (8).

Many studies have documented the reasons parents and children attend an ED for treatment. Parents and professionals acknowledge the importance of closer liaison between hospital and primary health care services (9). A survey reported that parents perceived illness to be severe and thought that their children may require diagnostic testing or other interventions mostly available within hospital setting (10). Parents also stated the accessibility and availability of ED services as another reason for attendance (8). A systematic review of reasons parents attend an ED with children with minor illnesses, found that poor accessibility of primary care appointments, lack of confidence in general practice (GP), advice from others and financial considerations were motivating factors (7) in deciding whether to attend an 
ED for assessment. Healthcare professionals have suggested lack of appointments at GP surgeries and parents' lack of knowledge of conditions that are true emergency as other mitigating factors $(\mathbf{8}, \mathbf{1 1})$.

The utilisation of EDs by parents of children with minor illnesses places undue burden on healthcare services resulting in long waiting times and strained resources (1). In an attempt to deal with this issue, NHS England (4) outlined plans to improve access to non-urgent care to ensure patients are given the best care at the right time and place. This move was to save cost, free the EDs to concentrate on urgent conditions and also meet the target of treating $95 \%$ of patients within 4 hours of attending an ED in 2018. To achieve this plan, integration of primary care services (PCS) within EDs for patients with non- urgent conditions was recommended (4). Each NHS Trust in England was asked to redesign their ED services to accommodate the new model of care. However, evidence suggest that only $40 \%$ of sites have a co-located primary care service (12). Of those EDs with integrated PCS, reduced wait times, timely care, patients' satisfaction and effective use of resources have been reported (13), supported by evidence from the Netherlands $(14,15)$. There is potential benefit of clinical and cost savings from on site primary care service through limited use of diagnostics and referrals for admission $(16,17)$.

Same Day Emergency Care is the provision of same day care for emergency patients who would otherwise be admitted to hospital. Under this care model, patients attending at hospital with relevant conditions can be rapidly assessed, diagnosed and treated without being admitted to a ward, and if clinically safe to do so, will go home the same day their care is provided. When a patient comes to 
hospital, a Same Day Care service (which may operate under the name of ambulatory emergency care unit) means patients with some medical concerns can be assessed, diagnosed, treated and safely discharged home the same day, rather than being admitted. The types of conditions that can be managed through Same Day Care will vary depending on the hospital and needs of the local population (18).

Given the potential benefits of a co-located SDC service within the ED, it is vital for this service to be accessible to all age groups. Within the study hospital, this service is not available to children under 16 years. The lack of access to children under 16 years of age could be viewed as age-discriminatory, contravening article 24 of the United Nations Convention on the Rights of the Child (UN CRC) (health and health services) (19) which stipulates the right of a child to the best possible health.

In the light of all of the above, this service evaluation study sought to examine why parents of children with minor health conditions chose to attend an ED and their views on alternative treatment facilities within the ED. Information collected in this study provides insight into the health seeking behaviour of the researched community, their knowledge and understanding of emergency conditions and their perception of alternative paediatric care facilities within an ED. This will enable the development of alternate models of emergency medicine care that address community expectations within the means of ED resources.

\section{RESEARCH QUESTIONS}


1. Why do parents of children with minor health conditions attend the local emergency department; and

2. How do parents perceive using a co-located paediatric same day care service within the emergency department as an alternative treatment facility for nonemergency conditions?

\section{Inclusion criteria (child)}

- Children aged under 16 years of age.

- Child assigned to Manchester Triage category 3, 4 or 5.

\section{Inclusion criteria (parent or carer)}

- Parent who was willing to complete questionnaire.

\section{Exclusion criteria (child)}

- All children under 16 years of age allocated category one and two in the triage process

\section{Exclusion criteria (parent or carer)}

- Parents who were too distressed or unwilling to complete the questionnaire.

The Manchester Triage System (MTS) is a clinical risk management tool used by clinicians worldwide to enable them to safely manage patient flow when clinical need far exceeds capacity. There are 53 MTS charts which are presentation, not diagnosis based. Charts are based on what the patient says is happening, not what may be the cause. The MTS uses common names, discriminators and definitions in order to 
maintain consistency, safety and to allow robust auditing. It is a reductive system, starting from the premise that the patient is presenting with a life-threatening condition and all high priority discriminators must be ruled out prior to reducing the patient priority. This ensures the safety of the system and that no serious patient conditions are missed. Decisions made regarding patient outcome are a clinical judgement made by the clinician. Although not designed as a streaming tool, the MTS can assist in streaming patients to the most appropriate pathway of care. However, the triage priority is a clinical indicator and is absolute; the management of particular patient will depend on department priorities and services available; management of patients should never be confused with a patient's clinical priority (20).

\section{ETHICAL APPROVAL}

Approval for this service evaluation study was given by the Research and Innovation Department at Salford Royal NHS Foundation Trust. It was determined that formal Research Ethics Committee approval was not required, and this is consistent with the Health Research Authority guidelines.

\section{METHOD}

\section{Study design and setting}

This service-improvement review study took place in the ED of an Acute NHS Hospital in the North West of England. It was a descriptive cross-sectional survey using a structured self-completed paper questionnaire with open questions to gather 
data. Questionnaires were distributed by senior nurses in the ED and it was those nurses that made the subjective assessment about whether a parent was too distressed to receive a copy of the questionnaire. Although no formal risk assessment protocol was in place, the professional discretion of the nurses working in the ED was relied upon to determine whether a parent was either too distressed to complete the questionnaire or their level of distress was increasing and it was felt inappropriate to continue completion of the questionnaire. Any distress evident after completion of the questionnaire was handled in accordance with usual departmental practise for emergency medicine. Questionnaires were returned directly to a member of nursing staff who retained them securely to be collected by a research nurse for analysis.

The questionnaire was adapted from a questionnaire developed at the Royal Hospital for Sick Kids, Edinburgh, UK (21). The questionnaire was validated by ED colleagues on face value and comprised of three sections:

1. You (parent or carer) / household;

2. Your visit to the ED; and

3. GP information.

The population surrounding the hospital where this study was undertaken is diverse. All attendees to the ED, with the exception of the exclusions set out above, were eligible to participate in this study even if English was not their first language. The hospital's interpreting service was made available for any participants who required it, to enable completion of the questionnaire. Questionnaires were anonymous and 
once completed were collected and stored in a locked cabinet within the study site. Formal consent was not sought as completion of the questionnaire was deemed by the study team and local research and innovation department as agreeing to participate in the study. This was made clear in the patient information sheet (PIS) and invitation to participate in the survey, which were provided by a senior nurse in the ED (and time given to read and consider whether the individual wished to participate or not).

\section{Sample and sample size}

Convenience sampling method (22) was used. Convenience sampling involves participants being selected because they were the easiest to recruit for the study (23). This pragmatic and relatively easy method was chosen given the ease of access to parents and carers in the waiting room of the ED. Two types of sampling method can be used to recruit participants to a study—random sampling (sometimes called probability sampling) and non-random sampling (sometimes called nonprobability sampling). Convenience sampling constitutes non-random (nonprobability) sampling.

Random sampling involves some form of random selection of the population members. Each population member has a known and typically equal probability of being selected. Simple random sampling (sometimes referred to simply as random sampling) is the most straightforward type of random sampling. A sampling frame is constructed-that is, a list of all people belonging to the population. Constructing a sampling frame requires knowledge of exactly who is in the population. A sample of a fixed size is selected at random from this list, with all members of the population 
having the same probability of being selected, independently of all others. The probability that a population member will be chosen is known in advance (23). In contrast, in this study, convenience sampling involved selecting patients because it was convenient and they were easily accessible. Despite the potential limitations of convenience sampling, it is often used to recruit participants to a study because it is easy to do (23).

This study was designed as a form of service evaluation, approved by the research and innovation department at the hospital. The aim was to recruit 50 participants which was felt to be an acceptable number $(24,25)$ broadly comparable with the number of patients often included in clinical audits. The attendances to the ED where this study was performed were as follows:

- Mean attendances per day (1 January 2019 - 31 December 2019): 81 patients

- Mean attendances per day during the ten-week study: 70 patients [reflecting lower attendances during the summer vacation period]

- Total attendances (1 January 2019 - 31 December 2019): 29586

All parents who met the inclusion criteria were offered the opportunity to complete a questionnaire. Recruitment took place over a ten week period between July and September 2019 inclusive of weekdays, weekends and nights to capture any variation in attendances. A total of 58 participants were recruited. A participant was defined as a person accompanying a child and who at least partially completed, and returned, a questionnaire. In this study questionnaires were returned from parents or 
carers of 58 children $-\mathrm{a}$ total of 58 questionnaires having been returned. More than one parent or carer may have accompanied a child however exactly the same number of questionnaires were returned as children's details provided. It is possible that more than one carer may have contributed to the questionnaire responses, but no more than one questionnaire was returned per child.

In summary, 58 parents and carers of 58 children were recruited to participate in this study. This was felt to be an adequate response for a service evaluation study.

\section{Data analysis}

80 questionnaires were distributed and 58 (73\%) were returned. Of these, 34 were fully completed (59\%) and 24 (41\%) did not complete the open-ended question. Nonetheless, all of the 58 returned questionnaires, whether fully or partially completed, were analysed as far as was possible from the data within them. Microsoft Excel was used to analyse quantitative data and qualitative data adduced from the free-text responses to the open-ended question were hand-coded to find themes. The qualitative responses were reviewed by two of the authors.

\section{RESULTS}

Of the 58 children whose parents or carers completed the questionnaires ("respondents"), there were more male children (64\%) than female (36\%) included. $48 \%$ of the children were between the ages of $0-4$ years old with $31 \%$ aged $5-9$ years old and $21 \%$ aged ten to 16 years old. $16 \%$ of the children were accompanied by both parents, $19 \%$ by the father only, and the majority were accompanied by their 
mother $62 \%$. Three percent of children were accompanied by someone other than a parent, for example a grandparent, an uncle, or an aunt. $93 \%$ of respondents had access to telephone. first-time parents.

[NOTE TO EDITOR: INSERT TABLE 1 APPROXIMATELY HERE] 
Table 1 : Demographics

\begin{tabular}{|c|c|c|}
\hline Variable & $n=58$ & Missing \\
\hline $\begin{array}{l}\text { Child's gender } \\
\text { Male } \\
\text { Female }\end{array}$ & $\begin{array}{l}37(64 \%) \\
20(34 \%)\end{array}$ & $1(2 \%)$ \\
\hline $\begin{array}{l}\text { Child's age (years) } \\
0-4 \\
5-9 \\
10-16\end{array}$ & $\begin{array}{l}28(48 \%) \\
18(31 \%) \\
12(21 \%)\end{array}$ & \\
\hline $\begin{array}{l}\text { Child accompanied by } \\
\text { Father } \\
\text { Mother } \\
\text { Other } \\
\text { Both parents }\end{array}$ & $\begin{array}{l}11(19 \%) \\
36(62 \%) \\
2(3 \%) \\
9(16 \%)\end{array}$ & \\
\hline $\begin{array}{l}\text { Telephone access } \\
\text { Yes } \\
\text { No }\end{array}$ & $\begin{array}{l}54(93 \%) \\
2(3 \%)\end{array}$ & $2(3 \%)$ \\
\hline $\begin{array}{l}\text { Economic status (parents) } \\
\text { Full time employment } \\
\text { Part time } \\
\text { Unemployed } \\
\text { Caring } \\
\text { Other }\end{array}$ & $\begin{array}{l}25(43 \%) \\
17(29 \%) \\
6(10 \%) \\
7(12 \%) \\
1(2 \%)\end{array}$ & $2(3 \%)$ \\
\hline $\begin{array}{l}\text { Time of ED attendance } \\
\text { 09:00 - 18:00 } \\
\text { 18:00 - 00:00 } \\
\text { 00:00 - 09:00 }\end{array}$ & $\begin{array}{l}42(72 \%) \\
14(24 \%) \\
2(3 \%)\end{array}$ & \\
\hline $\begin{array}{l}\text { Mode of transport } \\
\text { Own transport } \\
\text { Walked } \\
\text { Ambulance } \\
\text { Other }\end{array}$ & $\begin{array}{l}39(67 \%) \\
2(3 \%) \\
2(3 \%) \\
15(27 \%)\end{array}$ & \\
\hline $\begin{array}{l}\text { Previous ED attendances } \\
\text { Yes } \\
\text { No }\end{array}$ & $\begin{array}{l}51(88 \%) \\
7(12 \%)\end{array}$ & \\
\hline
\end{tabular}




\section{Parent status and ED attendance}

Most parents (43\%) had full time employment, $29 \%$ worked part time, ten percent were unemployed and $12 \%$ had a caring role, while two percent described their employment status simply as 'other'. The majority of attendances (72\%) were between the hours of 09.00 and 18.00. Only three percent attended between the hours of 00.00 and 09.00 and $24 \%$ between 18.00 and $00.00 .40 \%$ of attendees lived within 1 mile of the ED and $51 \%$ within three to five miles while nine percent did not disclose their postcode. The majority of attendees (67\%) came by their own transport, three percent arrived by ambulance, three percent walked to the ED and the remaining $27 \%$ used other means of transportation. When asked about previous attendances, 51 children (88\%) had received care in the ED previously and out of those 51 children, eight percent had attended between five and 11 times within a 12month period. 57\% visited up to four times within a year and 33\% (19) did not attend within the last year. Two percent of the participants did not complete this question.

[NOTE TO EDITOR: INSERT TABLE 2 APPROXIMATELY HERE] 
Table 2: Determinants of attendance

\begin{tabular}{|c|c|c|}
\hline Variable & $\mathrm{n}=(\%)$ & Missing \\
\hline $\begin{array}{l}\text { Reason for attendance } \\
\text { Injury } \\
\text { Illness } \\
\text { Not sure }\end{array}$ & $\begin{array}{l}27(47 \%) \\
16(28 \%) \\
15(26 \%)\end{array}$ & \\
\hline $\begin{array}{l}\text { How long ago injury/illness occurred } \\
\text { Within } 24 \text { hours of attendance } \\
24 \text { hours - } 1 \text { month } \\
1 \text { month - } 20 \text { months } \\
\text { Not sure }\end{array}$ & $\begin{array}{l}29(50 \%) \\
18(31 \%) \\
4(7 \%) \\
1(2 \%)\end{array}$ & $6(10 \%)$ \\
\hline $\begin{array}{l}\text { How serious is the child's condition } \\
\text { Very serious } \\
\text { Serious } \\
\text { Fairly serious } \\
\text { Not very serious } \\
\text { Not serious at all } \\
\text { Not sure }\end{array}$ & $\begin{array}{l}3(5 \%) \\
11(19 \%) \\
16(28 \%) \\
16(28 \%) \\
1(2 \%) \\
11(19 \%)\end{array}$ & \\
\hline $\begin{array}{l}\text { How worried are you } \\
\text { Very worried } \\
\text { Worried } \\
\text { Not very worried } \\
\text { Fairly worried } \\
\text { Not sure }\end{array}$ & $\begin{array}{l}11(19 \%) \\
19(33 \%) \\
10(17 \%) \\
17(29 \%) \\
1(2 \%)\end{array}$ & $1(2 \%)$ \\
\hline $\begin{array}{l}\text { Parental self-assessment of urgency of care } \\
\text { Straightaway } \\
\text { On the day } \\
\text { Could wait a few days }\end{array}$ & $\begin{array}{l}27(47 \%) \\
25(43 \%) \\
5(9 \%)\end{array}$ & $1(2 \%)$ \\
\hline
\end{tabular}




\section{Determinants of attendance}

Parents were asked to comment on the reasons for the ED attendance. Some parents (28\%) stated the reason was because of an illness, $47 \%$ because of injury and $26 \%$ were unsure. Results revealed that the illnesses or injuries which resulted in the attendance to the ED had begun up to 20 months prior to attendance (zero to 20 months). Half of the health problems first occurred within the 24 hours prior to the ED attendance, 31\% between 24 hours and one month prior to attendance and 7\% between one and 20 months prior to attendance. Two percent of participants were not sure of duration and ten percent of parents did not answer this question. The questionnaire also examined how parents perceived the seriousness of their child's condition. Only five percent of parents perceived their child's condition as very serious, $19 \%$ as serious, $28 \%$ not very serious, $28 \%$ fairly serious, three percent not serious at all and $19 \%$ were unsure.

When asked how worried parents were about their children's condition, 19\% responded that they were very worried, $33 \%$ were worried, $17 \%$ not very worried, $29 \%$ fairly worried, two percent were unsure and two percent did not answer the question.

[NOTE TO EDITOR: INSERT TABLE 3 APPROXIMATELY HERE] 
Table 3: Advice seeking/knowledge of alternative services

\begin{tabular}{|c|c|c|}
\hline Variables & $n=(\%)$ & Missing \\
\hline $\begin{array}{l}\text { Sought advice before ED attendance } \\
\text { Yes } \\
\text { No }\end{array}$ & $\begin{array}{l}27(47 \%) \\
28 \text { (48\%) }\end{array}$ & $3(5 \%)$ \\
\hline $\begin{array}{l}\text { Yes } \\
\text { GP } \\
\text { NHS111 } \\
\text { Pharmacist } \\
\text { Dentist } \\
\text { Relatives and friends } \\
999\end{array}$ & $\begin{array}{l}8(13 \%) \\
5(9 \%) \\
2(3 \%) \\
1(2 \%) \\
12(21 \%) \\
1(2 \%)\end{array}$ & $3(5 \%)$ \\
\hline $\begin{array}{l}\text { Aware of other services } \\
\text { More than one } \\
\text { At least one } \\
\text { Same day care for children under } 16\end{array}$ & $\begin{array}{l}24(42 \%) \\
26(44 \%) \\
0 \%\end{array}$ & $9(15 \%)$ \\
\hline $\begin{array}{l}\text { Registered with GP } \\
\text { Yes } \\
\text { No }\end{array}$ & $\begin{array}{l}53(91 \%) \\
2(3 \%)\end{array}$ & $3(5 \%)$ \\
\hline $\begin{array}{l}\text { Contacted GP before ED attendance } \\
\text { Yes } \\
\text { No }\end{array}$ & $\begin{array}{l}17(29 \%) \\
38(66 \%)\end{array}$ & $3(5 \%)$ \\
\hline $\begin{array}{l}\text { Reasons for not contacting GP }(66 \%) \\
\text { Surgery closed } \\
\text { Perceived urgency of care } \\
\text { GP cannot help with the problem } \\
\text { Other }\end{array}$ & $\begin{array}{l}19(50 \%) \\
6(17 \%) \\
3(8 \%) \\
2(5 \%)\end{array}$ & $5(13 \%)$ \\
\hline $\begin{array}{l}29 \% \text { who contacted GP } \\
\text { Advised to take child to ED } \\
\text { Wait to see if condition improves } \\
\text { Surgery closed }\end{array}$ & $\begin{array}{l}8(47 \%) \\
5(30 \%) \\
3(17 \%)\end{array}$ & $1(6 \%)$ \\
\hline $\begin{array}{l}\text { Wait time to see GP } \\
\text { Not applicable } \\
1-24 \text { hours } \\
2-4 \text { days } \\
2-3 \text { weeks }\end{array}$ & $\begin{array}{l}35(60 \%) \\
9(16 \%) \\
3(6 \%) \\
3(5 \%)\end{array}$ & $8(13 \%)$ \\
\hline
\end{tabular}




\section{Advice seeking/parental knowledge of other services}

Almost half of the parents (48\%) indicated they did not seek advice before attending the ED. $13 \%$ contacted their GP, $21 \%$ their relatives and friends, nine percent NHS 111, two percent 999, two percent dentist and three percent pharmacist. Five percent did not answer the question. One question examined parent's knowledge of alternative treatment facilities aside from ED and $42 \%$ said they are aware of more than one treatment services, $26 \%$ only knew of their GP surgery, three percent GP Out of Hours service, two percent NHS 111 (the non-emergency National Health Service telephone advice service in England), 12\% walk-in-centres and $15 \%$ did not respond to this question. No participant knew about co-located SDC services within an ED.

\section{GP services}

Out of the 58 participants, $53(91 \%)$ said their children were registered with a GP, three percent did not have a GP and five percent did not answer the question. When asked whether they contacted their GP before attending the ED, $66 \%$ said No, 29\% answered Yes and five percent did not answer the question. Of the $66 \%$ that did not contact their GP before coming to the ED, $50 \%$ of them stated that GP surgery was closed, $17 \%$ felt that their child needed urgent ED intervention and eight percent perceived that their GP unable to help with the problem. The remaining $13 \%$ did not provide their thoughts and five percent simply stated the reason as 'other'. Of those that contacted their GP before attending the ED, almost half $(47 \%)$ said they were told to take child to ED, $30 \%$ were advised to wait and see if condition improves, $17 \%$ stated their GP surgery was closed at time of contact and six percent did not respond to the question. Participants were also asked to shed light on how long they 
were told to wait before they could see a GP. $60 \%$ felt this question was not applicable with no reason provided, six percent said between two to four days, five percent between two to three weeks and $16 \%$ between one and 24 hours. $13 \%$ did not answer the question.

[NOTE TO EDITOR: INSERT TABLE 4 APPROXIMATELY HERE]

Table 4: Same day care service within ED

\begin{tabular}{l|l|l|}
\hline Variable & $n=(\%)$ & Missing \\
\hline $\begin{array}{l}\text { Would you be happy for your child with a non-urgent condition to } \\
\text { receive care from same day care? }\end{array}$ & $19(33 \%)$ & $24(41 \%)$ \\
Yes & $7(12 \%)$ & \\
No & $8(14 \%)$
\end{tabular}

The final question on the questionnaire was an open-ended question for participants to record their qualitative comments: 'Do you have any comments you would like to make about how you feel if your child was to be referred to a GP within A\&E department for treatment?'.

$41 \%$ of participants did not answer this question. Out of the $34(59 \%)$ that answered the question, the majority of parents $(n=19,33 \%$ ) said they would be happy to receive GP services within ED. Some parents recognised the work pressure within ED and suggested that providing a GP service would help lessen the burden, saying, 'our wonderful NHS is at full capacity and almost at breaking point, something 
is needed to relieve the hospitals'. Other parents commented that they would be happy if the right care is given and the waiting time is reduced, saying, 'as long as he is diagnosed and treated quickly makes no difference' and 'as long as my child's injury was treated by a qualified doctor or nurse' One parent commented, 'if the problem was something the GP could deal with that would be fine and 'I wouldn't mind as long as she received the care she needs and wait wasn't longer than usual'. Others believed that having an alternative treatment centre within the ED would be helpful, stating, 'the level of sickness bugs could be limited if there is a minors walk in department for things such as dressing wounds, gluing cut and an assessment place to see if you really require A\&E' and one parent commented that, 'children's walk in is definitely needed. A\&E too long'.

Seven parents $(12 \%)$ commented that they would not be happy to be referred to a GP. Some perceived that their children's condition were not suitable to be seen by a GP, saying, 'A\&E is the best department for the wound so GP would be not good' and 'I feel the GP couldn't deal with the issue as quickly and effectively and my child's condition was worsening'. Others believed that their children would get the best care in A\&E, saying, 'I feel my child would get the care and help he needs being in A\&E'.

One parent did not have confidence in alternative services as previous referrals to these services have been cancelled and their child's health deteriorated requiring urgent treatment. The remaining $14 \%$ commented on issues unrelated to the study 
(these comments were excluded from analysis) and $41 \%$ did not comment on this question.

\section{LIMITATIONS}

This manuscript describes the results of a small, single site descriptive crosssectional study which explores the reasons that parents bring their children and young people to the ED for non-urgent conditions, and their perceptions of on-site primary care services.

Aside from the obvious limitation of this being a small, single-site study, a further limitation of this study is that some participants omitted providing an answer to the final qualitative question in the questionnaire. There are a number of reasons why this may be the case including a potential flaw in the design of the question, the fact that the remainder of the questionnaire did not require free text writing (and therefore the last question may have been perceived as arduous to complete), the questionnaire design, literacy abilities of respondents or practical considerations such as whether the facilities were available (including a hard surface) for parents to write on. If this study were repeated, either locally or in another setting, the authors would strongly recommend efforts being made to consult more widely with an expert panel and members of the public in the design of the questionnaire. In addition, consideration could be given to administration of the questionnaire by a research nurse (or other suitable professional) not involved in the direct clinical care of the child. Improvements could be made to the questionnaire for future use for example by asking members of the public to review the questions or by using legibility screening software. 
It may have been more appropriate to validate the questionnaire using a small number of parents or non-healthcare volunteers to comment on layout and burden of completion - this may have highlighted the issue of the poor response to the final section prior to study distribution. In any future study the authors recommend that this pre-use validation occurs.

This was a small study undertaken in a district general hospital in England and it may be that the results might not be applicable to an ED in a tertiary care children's hospital. Additionally, this study was conducted in England and it may be that the study would need to be repeated in other jurisdictions, for example Scotland or other countries, which have different methods of urgent care delivery (including, for example, a different method of delivering the English NHS 111 service).

Convenience sampling was used in this study. The participants were not selected at random from the population - they were selected for inclusion because they happened to be easily accessible to the research team. Hence, it is possible that the views expressed by the participants may not be representative of the views of a wider population attending urgent and emergency care facilities. For this reason it is important for a local unit considering introduction of a same day care service to follow on from the results of this study with their own local investigation of the acceptability, and format, of a proposed same day care service to their own population of patients. 
It is recognised that only $59 \%$ of distributed questionnaires were completed in full with $41 \%$ of respondents choosing not to answer the final free-text question. It is recognised that this may have skewed the results, but to what extent is not certain, and that it is a limitation of the study.

\section{DISCUSSION}

This study intended to find out the reasons parents or carers chose ED for nonurgent health needs of children and their perception of receiving care from on-site same day care services. The findings showed that ED services were accessed by respondents irrespective of the perception of their child's condition, geographical location, their occupation and time of day. These findings are sufficient to report back to the hospital directors about parents' perceptions of a same day care service which will be useful in the design of local services in the future.

Consideration of what service-provision for urgent and emergency care is not just something that happens in England. Increasing numbers of hospital ED visits pose a challenge to health systems in many countries and reform approaches, including extending availability of urgent primary care, improving coordination between urgent primary care and concentrating emergency care provision at fewer institutions has been described in Australia, Denmark, England, France, Germany and the Netherlands (26). It has been suggested that better guidance of patients and a reconfiguration of emergency and urgent care are the most important measures to address the current challenges (26) - measures which are consistent with some of the central arguments in this study. 
In Italy a study, setting out to determine the extent of non-urgent visits to a public hospital ED, reported that a review of the attendances of 541 patients described $19.6 \%$ of these having attended with non-urgent conditions. Multiple logistic regression analysis showed that age and sex were significant predisposing factors for utilization of the ED for non-urgent visits, with the most frequent reason given by patients for their visit to the ED being that the patient believed their complaint to be an emergency (27). In this study, $24 \%$ of respondents felt their child's condition was serious or very serious and at least $50 \%$ were worried or very worried about their accompanying child.

A systematic review of studies that evaluated the effectiveness of introducing primary care professionals to hospital EDs to attend to non-urgent patients concluded that there is insufficient evidence upon which to draw conclusions for practice or policy regarding the effectiveness and safety of care provided to nonurgent patients by GPs in the ED to mitigate problems of overcrowding, wait-times and patient flow (28). Given the promotion of Same Day Emergency Care Services by NHS England, the findings in this study suggest that ED services are likely to be continuously utilised by parents and carers of children with non-urgent conditions and there is therefore a need to commission further research to look at evaluating those services and the impact they have on quality and effectiveness of patient care.

Internationally, for example, in the United States of America, it has been suggested that many ED visits could be managed at other urgent care centres and "retail clinics" however more research is needed to ensure that care of equivalent quality is 
provided (29). This is further evidence to support a full evaluation of Same Day Care Services being commissioned in England.

Previous studies found parents perceived ED services as reassuring and a one-stopshop that is packed with expertise, relevant treatments and interventions for their children therefore preferred the ED to other available services (30-34).

In this study $93 \%$ of the respondents had access to a telephone. This means $93 \%$ could have telephoned their GP or NHS 111 for advice before attending. It also means that, in the absence of a telephone, seven percent would have been unable to telephone their GP or NHS 111 before attending which might mean those services might need to more clearly promote that they are accessible by other routes such as smart telephone applications (GPs) or the internet (www.111.nhs.uk)

The majority of the children in the study attended the ED with minor injuries. Preceding studies suggest parents of injured children commonly perceive that it was an emergency (31) and were more likely to attend ED (35).

Respondents' concern appeared to have played a crucial role in ED attendance in the study. Over half of respondents expressed being worried or very worried about their child's wellbeing and an overwhelming majority stated treatment was required straightaway or on the day even though only a quarter reported their child's condition as serious and very serious. The evidence in this study suggested respondents, as has been highlighted in previous work involving views of patients, are not always 
capable of assessing a health problem to justify the legitimacy of their health needs (36). Respondents' level of anxiety, and concern about perceived seriousness of their child's condition, were varied, ranging from not worried to very worried. This wide range of levels of concern may mean emotional reasons that prompt perceived urgency of care could be intuitive rather than logical (7). Anxiety and perceived urgency for treatment have been identified as key factors parents chose to attend EDs $(30,32,37)$. In contrast, Amiel et al (38) did not identify psychological concern as a reason for attendance in a study which examined why patients with minor illness attended the ED.

$66 \%$ of respondents did not make contact with a GP prior to attending the ED with the reasons for lack of contact with a GP including a surgery being closed, perceived urgency of care required and a subjective decision being made that the GP would be unable to deal with the specific problem the child was suffering from. In addition, it is clear that further work needs to be done in the community to address the concerns raised by the $12 \%$ of respondents who commented that they would not be happy to be seen by a GP or who reported that the child's condition was not suitable to be assessed by a GP.

Interestingly of the $66 \%$ respondents who did not make contact with a GP prior to attending the ED (Table three), 50\% of respondents stated that they had attended the ED because the GP surgery was closed. One of the authors, who works clinically in an ED and regular has discussion with parents about primary care services, was aware that at the time many respondents believed the GP surgery to be closed, there was actually primary care provision available. Indeed, in England, GP services 
are available 24 hours a day, seven days a week (39). It is apparent to the authors, both from the individual discussions with respondents following submission of their questionnaires, and through the analysis of the quantitative and qualitative data in this study that a perceived lack of access and availability of GP services may be misconceived. The authors therefore recommend further enhanced communication systems regarding primary care services such as posters, appropriate door-to-door information (in multiple languages and tailored to different literacy levels) and, perhaps, education in schools (with the aim of trying to introduce inter-generational change) may be appropriate.

Nearly all respondents reported access-related issues ranging from lack of appointments at the GP surgery, to anticipated long wait times. The majority of respondents had full time employment and they stated the lack of availability of primary care services at a time convenient to them as a factor to accessing ED for non-urgent conditions.

Others perceived that primary care services were not adequate to meet their child's health needs as they were advised to either wait to see if child's condition improved or in some cases were advised to attend the ED. Most stated their GP surgery was closed at the time they needed to access healthcare.

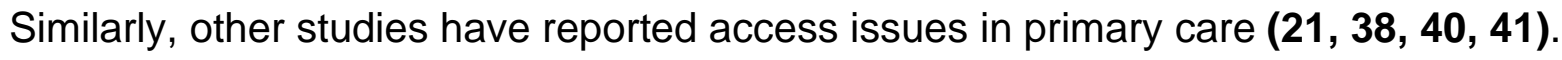
Difficulty in getting a GP appointment was not identified as a major issue in the Maguire et al (42) and Lega and Mengoni (43) reviews. Lack of out-of-hours services for minor conditions was identified by Berry et al (37) and Guttman et al (30) as a 
reason for ED attendance. Some respondents believed the ED provides 24 hours ready-care access and their attendance was not based on receiving specific treatment but on the readiness of the service (44).

The majority of children were registered with a GP but the proportion of respondents who contacted a GP prior to attendance was considerably lower than previously identified (45). Of those who made contact, almost half reported they were advised to either wait to see if the child's condition showed any improvement or to attend the ED. Preceding research suggests parents may refuse to utilise primary care services as they expressed they would be referred on to ED based on their previous experiences (10). Although seeking advice from someone other than the GP before attendance has been highlighted as one of the main determinants of attendance in Ogilvie et al (10), in this study almost half of the parents did not seek advice prior to attendance from any source.

In this study, $85 \%$ of respondents who completed the question on alternative services had knowledge of at least one alternative service. Interestingly no respondent was aware of on-site same day care services for children aged under 16 years. Studies have shown that people make decisions to attend EDs based on factors such as GP dissatisfaction (10), preference (21), inaccessibility of care (40) and reassurance (31-34).

The majority of the respondents in this study who shared their thoughts on same day care services were happy for their children to receive care from same day care services if appropriate and timely. Some of them acknowledged it might relieve ED 
and reduce wait times. However, some respondents were hesitant about such services and $41 \%$ of participants did not make comments which could be due to questionnaire design flaws, including whether those with lower literacy skills may have been disadvantaged by the requirement for free-text writing.

\section{CONCLUSIONS}

This study showed that ED services are likely to be continuously utilised by parents and carers of children with non-urgent conditions partly because of issues in accessing primary care services, lack of confidence in GPs, preference, and intuition with perceived urgency of care. Some respondents also expressed willingness to accept care from on-site SDC service for their sick children.

Therefore, establishing an on-site same day care services within the emergency department is not only logical but necessary as this may meet the demands of care, relieve the ED and accommodate parents' and carers' health seeking behaviour for their children.

\section{WORD COUNT}

6469 including abstract and tables.

\section{ABBREVIATIONS}

A\&E Accident and Emergency 
ED

Emergency Department

GP

General Practice

NHS

National Health Service

$\mathrm{OOH}$

Out of Hours

PCS

Primary Care Service

PIS

Patient Information Sheet

RCEM

Royal College of Emergency Medicine

SDC

Same Day Care Service

UK

United Kingdom

UN

United Nations 


\section{REFERENCES}

1. Butun A, Linden M, Lynn F, McGaughey J. Exploring parents' reasons for attending the emergency department for children with minor illnesses: a mixed methods systematic review. Emergency Medicine Journal. 2019;36(1):39-46.

2. Turner J, Coster J, Chambers D, Cantrell A, Phung VH, Knowles E. What evidence is there on the effectiveness of different models of delivering urgent care? A rapid review. Health Serv Deliv Res. 2015; 3 (43).

3. NHS Digital. Hospital Accident \& Emergency Activity 2018-19. Available from:

https://digital.nhs.uk/data-and-information/publications/statistical/hospital-accident--emergencyactivity/2018-19 [accessed 24 August 2020].

4. NHS England. Next steps on the NHS five year forward view. London: NHS England. 2017.

5. Ham C. Next steps on the NHS five year forward view. BMJ. 2017;357:j1678.

6. Shortell SM, Addicott R, Walsh N, Ham C. The NHS five year forward view: lessons from the United States in developing new care models. BMJ. 2015;350.

7. Butun A, Hemingway P. A qualitative systematic review of the reasons for parental attendance at the emergency department with children presenting with minor illness. International Emergency Nursing. 2018;36:56-62.

8. Fieldston ES, Alpern ER, Nadel FM, Shea JA, Alessandrini EA. A qualitative assessment of reasons for nonurgent visits to the emergency department: parent and health professional opinions. Pediatric emergency care. 2012;28(3):220-5.

9. Smith L, Daughtrey H. Weaving the seamless web of care: an analysis of parents' perceptions of their needs following discharge of their child from hospital. Journal of advanced nursing. 2000;31(4):812-20.

10. Ogilvie S, Hopgood K, Higginson I, Ives A, Smith JE. Why do parents use the emergency department for minor injury and illness? A cross-sectional questionnaire. JRSM open. 2016;7(3):2054270415623695.

11. Kraaijvanger N, van Leeuwen $\mathrm{H}$, Rijpsma D, Edwards M. Motives for self-referral to the emergency department: a systematic review of the literature. BMC health services research. 2016;16(1):685.

12. Murphy K, Mann C. Time to Act: Urgent Care and A\&E. The Patient Perspective. London: Royal College of Emergency Medicine \& The Patients Association. 2015.

13. O'Neill S, Wolters A, Steventon A. Briefing: The impact of redesigning urgent and emergency care in Northumberland. 2017.

14. Bosmans JE, Boeke AJ, van Randwijck-Jacobze ME, Grol SM, Kramer MH, van der Horst HE, et al. Addition of a general practitioner to the accident and emergency department: a cost-effective innovation in emergency care. Emergency medicine journal. 2012;29(3):192-6. 
15. Boeke AJP, van Randwijck-Jacobze ME, de Lange-Klerk EM, Grol SM, Kramer MH, van der Horst HE. Effectiveness of GPs in accident and emergency departments. British Journal of General Practice. 2010;60(579):e378-e84.

16. Khangura JK, Flodgren G, Perera R, Rowe BH, Shepperd S. Primary care professionals providing non-urgent care in hospital emergency departments. Cochrane Database of Systematic Reviews. 2012(11).

17. Fisher R, Thorlby R, Alderwick H. Briefing: Understanding primary care networks. The Health. 2019.

18. NHS England. The NHS long term plan. 2019.

19. United Nations. United Nations Convention on the Rights of the Child: United Nations; 1989. Available from: https://www.unicef.org.uk/what-we-do/un-convention-child-rights/[accessed 24 August 2020].

20. Mackway-Jones K, Marsden J, Windle J. Emergency triage: Manchester triage group: John Wiley \& Sons; 2014.

21. Hendry S, Beattie TF, Heaney D. Minor illness and injury: factors influencing attendance at a paediatric accident and emergency department. Archives of Disease in Childhood. 2005;90(6):62933.

22. Creswell JW, Creswell JD. Research design: Qualitative, quantitative, and mixed methods approaches: Sage publications; 2017.

23. Sedgwick P. Convenience sampling. BMJ. 2013;347:f6304.

24. Browne RH. On the use of a pilot sample for sample size determination. Statistics in medicine. 1995;14(17):1933-40.

25. Julious SA, Owen RJ. Sample size calculations for clinical studies allowing for uncertainty about the variance. Pharmaceutical Statistics: The Journal of Applied Statistics in the Pharmaceutical Industry. 2006;5(1):29-37.

26. Baier N, Geissler A, Bech M, Bernstein D, Cowling TE, Jackson T, et al. Emergency and urgent care systems in Australia, Denmark, England, France, Germany and the Netherlands-Analyzing organization, payment and reforms. Health Policy. 2019;123(1):1-10.

27. Bianco A, Pileggi C, Angelillo IF. Non-urgent visits to a hospital emergency department in Italy. Public health. 2003;117(4):250-5.

28. Gonçalves-Bradley D, Khangura JK, Flodgren G, Perera R, Rowe BH, Shepperd S. Primary care professionals providing non-urgent care in hospital emergency departments. Cochrane Database of Systematic Reviews. 2018(2).

29. Weinick RM, Burns RM, Mehrotra A. Many emergency department visits could be managed at urgent care centers and retail clinics. Health affairs. 2010;29(9):1630-6. 
30. Guttman N, Zimmerman DR, Nelson MS. The many faces of access: reasons for medically nonurgent emergency department visits. Journal of Health Politics, Policy and Law. 2003;28(6):1089120.

31. Stanley R, Zimmerman J, Hashikawa C, Clark SJ. Appropriateness of children's nonurgent visits to selected Michigan emergency departments. Pediatric emergency care. 2007;23(8):532-6.

32. Graham JM, Fitzpatrick EA, Black KJ. " My Child Can't Keep Anything Down!": Interviewing Parents Who Bring Their Preschoolers to the Emergency Department for Diarrhea, Vomiting, and Dehydration. Pediatric emergency care. 2010;26(4):251-6.

33. Brousseau DC, Nimmer MR, Yunk NL, Nattinger AB, Greer A. Nonurgent emergencydepartment care: analysis of parent and primary physician perspectives. Pediatrics. 2011;127(2):e375-e81.

34. Gawronski $\mathrm{O}$, Cerulli $\mathrm{C}$. Non-urgent use of the Emergency Department of the Bambino Gesù Hospital: a cross sectional survey of parents' motivations. Paediatrics and Child Health. 2009;19:S90S3.

35. Truman CD, Reutter L. Care-giving and care-seeking behaviours of parents who take their children to an emergency department for non-urgent care. Canadian journal of public health. 2002;93(1):41-6.

36. Masso M, Bezzina AJ, Siminski P, Middleton R, Eagar K. Why patients attend emergency departments for conditions potentially appropriate for primary care: reasons given by patients and clinicians differ. Emergency Medicine Australasia. 2007;19(4):333-40.

37. Berry A, Brousseau D, Brotanek JM, Tomany-Korman S, Flores G. Why do parents bring children to the emergency department for nonurgent conditions? A qualitative study. Ambulatory Pediatrics. 2008;8(6):360-7.

38. Amiel C, Williams B, Ramzan F, Islam S, Ladbrooke T, Majeed A, et al. Reasons for attending an urban urgent care centre with minor illness: a questionnaire study. Emergency Medicine Journal. 2014;31(e1):e71-e5.

39. Choose well Manchester. NHS 111 Service: NHS. Available from: http://www.choosewellmanchester.org.uk/self-care/nhs-111-service/ [accessed 24 August 2020].

40. Shearer FM, Bailey PM, Hicks BL, Harvey BV, Monterosso L, Ross-Adjie G, et al. Why do patients choose to attend a private emergency department? Emergency Medicine Australasia. 2015;27(1):62-5.

41. Palmer C, Jones K, Jones PA, Polacarz S, Evans G. Urban legend versus rural reality: patients' experience of attendance at accident and emergency departments in west Wales. Emergency medicine journal. 2005;22(3):165-70.

42. Maguire S, Ranmal R, Komulainen S, Pearse S, Maconochie I, Lakhanpaul M, et al. Which urgent care services do febrile children use and why? Archives of disease in childhood.

2011;96(9):810-6. 
43. Lega F, Mengoni A. Why non-urgent patients choose emergency over primary care services? Empirical evidence and managerial implications. Health policy. 2008;88(2-3):326-38.

44. Wood T, Cliff K. Accident and emergency departments-why people attend with minor injuries and ailments. Public health. 1986;100(1):15-20.

45. Williams A, O'Rourke $P$, Keogh S. Making choices: why parents present to the emergency department for non-urgent care. Archives of disease in childhood. 2009;94(10):817-20. 